\section{La lucha de los pueblos originarios en México por el reconocimiento de sus derechos}

\section{The struggle of indigenous peoples in Mexico for the recognition of their rights}

\author{
Alex Munguía Salazar ${ }^{1}$ \\ Lourdes Guadalupe Delgadillo Díaz LeaL ${ }^{2}$
}

Silvano Victoria de la Rosa ${ }^{3}$

La visión de los hijos y nietos de quienes fueron vencidos -que hoy están decididos a no serlo más- se muestra en este conjunto de testimonios que nos hablan de 'lo que siguió' hasta llegar al presente.

Su voz es de resuelta afirmación. No piden favor o limosna. Los pueblos originarios exigen ser escuchados y tomados en cuenta. Conocen sus derechos y por ellos luchan. La palabra, con la dulzura del náhuatl y de otras muchas lenguas vernáculas de México, comienza a resonar con fuerza. En un mundo amenazado por una globalización rampante, es ella prenuncio de esperanza. Nos hace ver, entre muchas cosas, que las diferencias de lengua y cultura son fuente de creatividad perdurable.

(León Portilla, 2002)

El México profundo está formado por una gran diversidad de pueblos, comunidades y sectores sociales que constituyen la mayoría de la población del país. Lo que los une y los distingue del resto de la sociedad mexicana es que son grupos portadores de maneras de entender el mundo y organizar la vida que tienen su origen en la civilización mesoamericana, forjada aquí a lo largo de un dilatado y

complejo proceso histórico.

(Bonfil Batalla, 2006)

No tienen cara, sino brazos; no practican cultura, sino folclore; no hacen arte sino artesanía, no profesan religiones, sino supersticiones...

(Galeano, Poema los nadies) 


\section{Resumen}

En las últimas décadas, la demanda de autonomía se ha convertido en una bandera de lucha para los pueblos indígenas de México y América Latina. Sin embargo, el término autonomía, debido a sus distintos usos e implicaciones en las normas internacionales, genera confusión y temores separatistas en los Estados. En la conceptualización y formulación de la autonomía se encuentran diversas ideas y propuestas, cuyos alcances van desde el ámbito regional y municipal hasta lo local. Ello complica aún más el cumplimiento de tan importante demanda. La autonomía es así una demanda central del conjunto de reivindicaciones asociadas a los derechos indígenas que actualmente también se debaten en el marco internacional y al interior de numerosas naciones. Esta demanda se refiere a la autodeterminación de los pueblos, básicamente en sus espacios geográficos propios, en su mayoría de tipo rural. La condición pluriétnica como base del establecimiento de ámbitos de autonomía indígena ya inició; al respecto destaca el caso de Canadá, en el cual los derechos territoriales también abarcan los recursos naturales. Inclusive, en América Latina en Bolivia, Venezuela, Colombia y Nicaragua la autonomía indígena ha sido elevada a rango constitucional.

Palabras clave: Derechos indígenas, autonomía, asimilación, sociedad pluriétnica.

\section{Abstract}

In recent decades, the demand for autonomy has become a banner of struggle for the indigenous peoples of Mexico and Latin America. However, the term autonomy, due to their different uses and implications on international standards, creates confusion and separatists fears in the States. In the conceptualization and formulation of autonomy there are various ideas and proposals, the scopes ranging from regional and municipal level to the local. This further complicates the fulfilment of this important demand. Autonomy is thus a central demand of all claims associated with indigenous rights, also discussed in the international arena and within many nations. This application refers to selfdetermination of peoples, basically in their own geographical areas, mostly rural type. The multiethnic condition as a basis for the establishment of areas of indigenous autonomy has already begun, highlighting the case of Canada where land rights also include natural resources. Even in Latin America, the cases of Bolivia, Venezuela, Colombia and Nicaragua in which indigenous autonomy has been elevated to constitutional status.

Keywords: indigenous rights, autonomy, assimilation, multiethnic society

\section{Introducción}

El término indígena proviene del latín antiguo indu, "en", "dentro"; acusativo de indigens, "necesitado", "pobre" y alusivo a "originario", "nativo", "no introducido". Se refiere también a un individuo que se encuentra en situación de pobreza, en ocasiones extrema. (Sotres Mutio, 2003).

La palabra 'indio' es sugerente por la confusión de la que nace. Pero, superado el error, el término 'indio' no dejó de aplicarse a esos pueblos. Mantener 
el nombre remite a la primera confusión, pero sobre todo, a una primera sustancial negación; esos pueblos debían ser llamados como si no fueran lo que son, sino otros: 'indios'. La idea 'indio americano' es una invención europea más que un descubrimiento, de ahí la polémica sobre la naturaleza humana o inhumana del indio. El 'indio' de América ingresó en la nueva invención europea del mundo con un nombre que no le pertenecía y como un ser negado en su especificidad social y humana. Para el europeo, 'indio' era 'el otro', el que resentía el embate de la conquista y de la acción colonial. Debido a ello, en la opinión europea sobre los pueblos americanos se relaciona al supuesto 'indio' con otros términos: bárbaro, grosero, inhumano, antropófago, natural y salvaje, además de tonto y crédulo, por ejemplo. (Montemayor, 2001, p. 23)

En 1789 el Diccionario de la Academia Francesa introdujo otro vocablo y lo relacionó con la palabra 'indio': indígena. "Este último vocablo proviene de dos partículas arcaicas del latín: indu (que significaba 'en') y geno (que significaba 'engendrar', 'producir'). Virgilio y Tito Livio utilizaban el término indígena para designar al pueblo latino originario y así distinguirlo de las personas nacidas en otro lugar" (Montemayor, 2001, p. 23).
Desde entonces, particularmente a partir del siglo XIX, es utilizado en la mayor parte de los países para designar a cada miembro de su población originaria. Indígenas son aquellos que nacen en una región, o los pueblos originarios de una región específica. Sin embargo, al ser un término que generaliza, asimismo empobrece la diversidad social de los pueblos originarios, como los americanos. El término indígena no alcanza a identificar a ninguno de los pueblos singulares que resisten desde hace 500 años en tierras americanas. La palabra "indio" agrega a esta indiferencia social la confusión de un remoto pasado en el que Europa se negaba a reconocer no solo a una nueva tierra, sino a sus pobladores.

\section{La cuestión indígena en México}

Los 'indios' de México nunca han sido 'indios' de México. Son pueblos que han tenido nombres precisos desde antes del siglo XV hasta la actualidad. Por ello, es necesario aprender a observar el territorio americano, sus recursos naturales, su flora y fauna, pero también a sus habitantes, sobre todo a los originarios. (Montemayor, 2001, p. 26)

Aunque en sentido estricto los diversos estudiosos de la cuestión indígena tienden a utilizar ambos términos, 
indio e indígena, lo cierto es que los dos designan a una fracción de la población desfavorecida y, además, al menos en primera instancia, utilizarlos implica segregación y generalización. No obstante, debe evitarse su uso generalizado y conviene más señalar la individualidad de cada grupo indígena, si bien no es fácil debido a la amplitud de dicha información.

Los indígenas son considerados como tales no sólo porque hablan lenguas originales, se visten y alimentan a la manera de sus antepasados, sino también porque han conservado los remanentes del modo de producción prehispánico que se manifiesta por ejemplo en sus técnicas agrícolas, sus usos, costumbres y relaciones en general. (Pozas, 1998, p. 17)

La nación mexicana presenta un panorama social altamente diversificado. México es un país de una gran diversidad cultural. Los pueblos indígenas son de los que más contribuyen con su patrimonio a la riqueza social y cultural de la nación. Estos pueblos están integrados aproximadamente por 19 millones de personas, que constituyen más de la décima parte de la población mexicana, distribuidos en cerca de 20 mil localidades y son los que más aportan en recursos humanos, naturales, territoriales y culturales, a pesar de ser los más pobres de los mexicanos. En México habita el $26 \%$ de toda la población indígena latinoamericana.

México ocupa el octavo lugar en el mundo, entre los países con la mayor cantidad de pueblos indígenas; se hablan más de 100 lenguas, de las cuales los pueblos indígenas aportan a esta riqueza cuando menos 60 . Nuestro país tiene una superficie de casi 2 millones de kilómetros cuadrados. Los grupos mexicanos indígenas poseen, en las regiones en las que viven, una superficie que abarca la quinta parte del territorio nacional. En 10 entidades mexicanas se concentran 5.4 millones, los restantes están diseminados en las otras entidades. De los 2428 municipios, en los que se encuentra dividida la nación, los prioritariamente indígenas ascienden a 803.

El $70 \%$ de los recursos petroleros se extrae de yacimientos marinos y terrestres del trópico mexicano, los más importantes corresponden a los Estados de Campeche, Tabasco y Chiapas, en municipios con una fuerte presencia indígena. Las principales presas hidroeléctricas del país: La Angostura, Malpaso, Chicoasén, Aguamilpa y Presidente Alemán se ubican y se abastecen de agua en los territorios indígenas.

Los ejidos y comunidades agrarias en municipios indígenas mexicanos tienen en propiedad el $60 \%$ de la vegetación arbolada, principalmente de bosques templados y selvas húmedas. Además, los pueblos 
indígenas aportan el 67\% de su población ocupada a las actividades agrícolas, mientras que el resto de la nación solo colabora con menos del $22 \%$. Y, principalmente, las áreas naturales protegidas se encuentran en municipios indígenas. Muchas de ellas son territorios sagrados $y$ ceremoniales, con zonas arqueológicas que los pueblos indígenas reclaman como suyas (Rosas, 1995, p. 32).

En México se hablan alrededor de 62 lenguas indígenas, además de diversas variantes dialectales que en ocasiones son incluso ininteligibles entre sí. Esta característica pluriétnica representa un importante patrimonio cultural desarrollado a lo largo del tiempo, que se expresa en conocimiento y relación con la naturaleza, en historias, mitos y leyendas, música, canto y danza, objetos de arte, entre muchas otras expresiones culturales. Se trata de un enorme patrimonio de la nación: un acervo de la riqueza del México del siglo XXI.

Como ya se mencionó, existen diversos criterios para cuantificar la población indígena de México. La CDI consideró que la estimación elaborada por el Consejo Nacional de Población (CONAPO), a partir de los datos censales recabados por el Instituto Nacional de Estadística, Geografía e Informática (INEGI), ha sido adecuada para conocer la cantidad de población indígena del país. De conformidad con tal estimación, la población indígena en México es de 12.7 millones de personas, lo que representa el 13\% de la población nacional.

La proporción de la población indígena estimada para 1990 y 1995 por INI-CONAPO y para 2000 por CDIPNUD se mantiene en diez indígenas por cada cien habitantes del país. Las entidades cuya proporción de población indígena es mayor a la nacional son las regiones centro, sur y sureste del territorio nacional: Yucatán (59\%), Oaxaca (48\%), Quintana Roo (39\%), Chiapas (28\%), Campeche (27\%), Hidalgo (24\%), Puebla (19\%), Guerrero (17\%), San Luis Potosí y Veracruz $\left(15 \%\right.$, cada uno). ${ }^{4}$

Al reconocimiento y valoración del pasado indígena, que históricamente se han dado en México y que han tenido mucho que ver con la construcción de una identidad nacional, no ha correspondido la capacidad de ofrecer a los pueblos indígenas, en el presente, condiciones mínimas de salud, educación y bienestar, así como de expresión de sus culturas en igualdad de condiciones que el resto de los mexicanos. ${ }^{5}$

Sin embargo, aún suele confundirse la obtención de los servicios básicos (agua, luz, drenaje, por ejemplo) con el desarrollo de las comunidades indígenas, por lo que es fundamental

4 CDI. $h t t p: / / w w w . c d i . g o b . m x / i n d e x . p h p ? i d$ seccion=90. Diversidad etnolingüística. Julio 2007.

5 CDI. http://www.cdi.gob.mx/index.php?id_ seccion $=399$. Indicadores socioeconómicos. Agosto 2007. 
recordar que proporcionar dichos servicios es la obligación de cualquier Estado y no un beneficio especial, y mucho menos implica el reconocimiento de las demandas indígenas en la actualidad nacional.

El sector indígena es comúnmente asociado con la pobreza. Las condiciones de desigualdad en las que viven los pueblos indígenas con respecto al resto de la sociedad también se reflejan en el ámbito educativo, en el entendido de que la pobreza es la carencia de los medios adecuados para solventar las necesidades básicas de las personas, incluyendo, por supuesto, el derecho a la educación.

En México, los problemas educativos en las regiones indígenas están vinculados a múltiples factores intrínsecamente asociados con la pobreza extrema y la marginación. Las localidades primordial y medianamente indígenas se caracterizan por su gran dispersión, lo que dificulta aún más la introducción de los servicios. Aunado a esto, prevalecen otros problemas propios de la pobreza extrema, tales como la desnutrición, las enfermedades gastrointestinales y respiratorias e, incluso, se observa la persistencia de las 'enfermedades residuales' (tuberculosis, paludismo, bocio, entre otros), la migración, el trabajo infantil asalariado y no asalariado, pero necesario en ocasiones para la subsistencia del núcleo familiar, y el bajo nivel educativo que, en general, se presenta en las zonas rurales.

\section{La lucha indígena nacional}

La perspectiva histórica muestra que la tensión entre las etnias, el Estado y la nación es antigua y ha sido persistente en México.

En diferentes momentos históricos cada una de esas entidades reclamó autonomía e identidad propias, y así generó una relación antagónica con las otras. Esos conflictos no fueron seguidos por una política efectiva de integración nacional que unificara los distintos componentes del cuerpo social y al mismo tiempo respetara sus tradiciones, particularmente la trayectoria de las comunidades indígenas, las únicas asentadas en una cultura propia, nacida y desarrollada en América. En lugar de unidad entre el proyecto nacional y las etnias indígenas, se manifestó una separación cada vez más honda. (Labastida, 2001, p. 394)

La historia reciente de México, la de los últimos 500 años, es la historia del enfrentamiento permanente, en ocasiones violento, entre quienes pretenden encauzar al país en el proyecto de la civilización occidental y quienes resisten arraigados en formas de vida de estirpe mesoamericana. La adopción del modelo occidental ha dado lugar a que se cree, dentro de la sociedad mexicana, una especie de país minoritario que se organiza de acuerdo con una sociedad 
distinta a la originaria. Las normas, maneras y propósitos de la civilización occidental no son compartidos (o lo son desde otra perspectiva) por el resto de la población nacional originaria; a ese sector, que impulsa el proyecto dominante puede llamársele México imaginario. Las relaciones entre el México profundo y el México imaginario han sido conflictivas durante cinco siglos que lleva su confrontación. "El proyecto occidental del México imaginario ha sido excluyente y negador de la civilización mesoamericana; no ha habido lugar para una convergencia de civilizaciones para dar paso a un nuevo proyecto de nación, diferente de los dos originales, pero nutrido de ellos" (Bonfil Batalla, 2006, p. 21).

México es una nación constituida a partir de la cultura y territorios de sus pueblos originarios. Los pueblos indígenas actuales conservan la herencia de culturas que mundialmente son reconocidas por sus adelantos científicos, políticos, sociales y culturales, tales como la mexica o la maya. Pese a que existen en territorio mexicano casi un centenar de pueblos distintos, con sus particulares idiomas, tradiciones, usos y costumbres, todos responden a principios comunes fundamentales, particularmente el derecho colectivo o concepción de comunidad como centro de su organización económica, política, social y cultural.

Durante la guerra de Conquista, los españoles desarrollaron una estrategia de aislamiento y persecución de todos los pueblos que encontraban. Inclusive, emprendían campañas militares "de pacificación" para reclamar para sí territorios, riquezas y hombres. Aún en la actualidad no es posible saber con precisión cuántos fueron los pueblos que desaparecieron completamente ante el expansionismo ibérico. Además, los pueblos sobrevivientes fueron sometidos a olvidar y renegar de su cultura, bajo pena de tortura y muerte. Los principales argumentos de los conquistadores para asesinar sabios indígenas fue la acusación de llevar a cabo prácticas de supuesta idolatría, brujería, hechicería o herejía.

A lo largo de la Colonia (de los siglos XVI al XIX) se tienen documentadas numerosos levantamientos indígenas en contra de la esclavitud y la situación de explotación del sistema de encomiendas de la Nueva España. La guerra de Independencia (de 1810 a 1821) fue protagonizada también en muchas de sus batallas principales por cuerpos armados de los más distintos pueblos indígenas; no obstante, el uso que se hizo de las poblaciones indígenas a favor del poder criollo en contra de los grupos peninsulares, sobre todo en la primera etapa de la Independencia, en la defensa de la causa de Fernando VII y en contra de la invasión de Napoleón I a España. Es hasta una superior etapa cuando se buscó la auténtica autonomía de la población mexicana frente a la Corona española y la abolición de la esclavitud.

Por ello, afirma Guillermo Bonfil (2006, p. 21): 
La mancuerna de poder $y$ civilización occidental, en un polo, y sujeción y civilización mesoamericana en el otro no es una coincidencia, sino el resultado necesario de una historia colonial que hasta ahora no ha sido cancelada en el interior de la sociedad mexicana. La descolonización de México fue incompleta: se obtuvo la independencia frente a España, pero no se eliminó la estructura colonial interna.

Así, los diversos proyectos nacionales conforme a los cuales se ha pretendido organizar a la sociedad mexicana en los distintos períodos de su historia independiente han sido en todos los casos proyectos encuadrados exclusivamente en el marco de la civilización occidental, en los que la realidad del México profundo no tiene cabida y es contemplada únicamente como símbolo de atraso y obstáculo a vencer.

El México profundo, entre tanto, resiste apelando a las estrategias más diversas según las circunstancias de dominación a la que es sometido. No es un México pasivo, estático, sino que vive en tensión permanente; los pueblos del México profundo callan o se rebelan, según una estrategia afinada por siglos de resistencia, concluye Bonfil.

Ya en la época independiente son famosas las batallas que ejércitos in- dígenas libraron durante las continuas entre centralistas y republicanos. En esos años también se llevaron a cabo guerras contra ejércitos invasores, resultado de las cuales México perdió importantes fracciones de su territorio ante el expansionismo estadounidense. En los territorios perdidos por México, quedaron decenas de pueblos indígenas, que serían perseguidos en las contiendas de colonización de la entonces costa oeste de EEUU, para finalmente ser confinados a reservaciones.

Explica Carlos Montemayor:

Cuando la llamada Guerra de Castas, José María Luis Mora era embajador en Inglaterra. En 1848 solicitó al gobierno inglés que ayudara a reprimir a los indios de Yucatán que perseguían con 'inaudita barbarie el designio de exterminar la raza blanca'. El ministro Palmerson replicó: 'nada es a ustedes tan importante ahora como el blanquear su población'; es decir, emprender una nueva colonización con grupos europeos. Mora tomó en serio esa indicación y reiteró oficialmente la necesidad de fusionar todas las razas y 'colores', mediante una colonización que favoreciera a los colonos blancos por encima de los 'indios', porque los 'indios' eran únicamente capaces de 'odios irreconciliables' y "revoluciones sangrientas". (Bonfil Batalla, 2006, p. 22) 
Gonzalo Aguirre Beltrán expuso este conflicto de los grupos liberales. La presencia indígena en la vida nacional implicó la necesidad imperiosa de asignarle una nueva identidad. Para los liberales del siglo XIX el "indio" era una carga que la Colonia había heredado a la nación, un obstáculo para el desarrollo y la modernidad.

Los gobiernos partieron de esta supuesta inferioridad y se propusieron redimirlos en algunos casos mediante una nueva esclavitud, por la represión, por la educación o, en el siglo XX, por su incorporación a la sociedad nacional y a los "beneficios" de la civilización moderna (Bonfil Batalla, 2006).

Es decir, "al finalizar la contienda entre liberales y conservadores se impone el programa liberal, el cual propicia que las corporaciones indígenas fueran despojadas de su derecho a la propiedad convirtiéndola en propiedad privada. Así, el indígena se convierte en agricultor pobre y explotado" (Bonfil Batalla, 2006: p. 22).

Más tarde, en la guerra contra la Intervención Francesa, el Ejército de México, compuesto principalmente por indígenas zacapoaxtlas, derrotó el 4 y 5 de mayo de 1862 al ejército imperial de Napoleón III y, posteriormente, concluyó el Segundo Imperio de Maximiliano de Habsburgo (1864-1867).

Una vez restaurada la República y siendo presidente Benito Juárez, indígena zapoteco de Oaxaca, se emprende la reconstrucción del país con base en un programa liberal. Sin embargo, con la intención de reactivar la economía, desamortiza los bienes de la iglesia y promueve la desaparición de la tenencia colectiva de la tierra por parte de los pueblos indígenas. Su proyecto era privatizar la tierra para que así pudiera comercializarse libremente.

La Constitución liberal de 1857, al declarar ciudadanos iguales a todos los habitantes de la República, privó a los grupos étnicos del derecho que amparaba sus formas de vida comunitaria, los despojó de personalidad jurídica para defender sus tierras y no proveyó ninguna legislación social a su favor. (Labastida, 2001, p.395)

Entonces, según Julio Labastida, en ese siglo los pueblos indígenas se convirtieron además en parias políticos, ya que ni el Estado ni los partidos políticos defendieron su causa. Por el contrario, se apoderaban de sus tierras, destruían las instituciones que cohesionaban las identidades étnicas y combatían las tradiciones, la cultura y los valores indígenas. De este modo, desde la República misma se forjó una triple oposición contra el mundo indígena.

La primera fue profundizada por las élites dirigentes, el partido liberal y el conservador, que rechazaron a los grupos indígenas como parte consti- 
tutiva de sus proyectos políticos. La segunda fue la oposición que se configuró entre el Estado y los diversos grupos étnicos, a los cuales el primero declaró la guerra cuando estos no se avinieron a sus leyes y mandatos. La tercera fue una resultante de las dos anteriores: la exclusión de los grupos indígenas del proyecto nacional. La consecuencia de esa triple contradicción fue la serie de explosiones indígenas.

El agravio a los pueblos indígenas más evidente de la actitud estatal fue no reconocerlos como comunidades merecedoras de un lugar digno en la República que construían los grupos dirigentes. Desde la Independencia, los autores de los proyectos nacionales trataron al indígena igual o peor que los conquistadores del siglo XVI. Por ejemplo, en el siglo XIX ni siquiera se encuentra una figura semejante a la de Bartolomé de Las Casas o Francisco Javier Clavijero.

$\mathrm{El}$ ataque a los valores y las tradiciones indígenas alimentó una conciencia social excluyente que condujo a la intolerancia del otro ser. Tal es el señalamiento que calificaba a los pueblos indígenas como enemigos del progreso o la acusación de que eran culpables del atraso y los fracasos del país.

Es decir, se difundió una imagen degradada y salvaje de la población indígena, que se generalizó en ese siglo y se adentró en las partes más profundas de la conciencia nacional. Solo de manera excepcional y en la medida en que les consideraron como trabajadores aprovechables algunos sectores les defendieron (Labastida, 2001).

Quienes tuvieron control sobre la decisión de los asuntos públicos pensaron que la solución de los problemas nacionales estaba en la gente blanca y extranjera, no en los antiguos pobladores. Por ello, ofrecieron las mejores tierras a una ilusoria migración europea que nunca llegó y despojaron de sus propiedades ancestrales a los hijos naturales del país. El resultado de esa política implacable fue la separación económica, social y espiritual entre la llamada 'gente decente' y las mayorías indígenas y campesinas.

Esta situación fue llevada al extremo por el Estado que surgió en la segunda mitad del siglo XIX, obsesionado por implantar los principios del liberalismo europeo, aun cuando esos valores chocaran con los tradicionales de la mayoría de gente en México. El vehículo que integró esas nuevas funciones del Estado fue el nacionalismo, una ideología que se desarrolló con gran fuerza después de las invasiones norteamericana $\mathrm{y}$ francesa. (Labastida, 2001).

Posteriormente, uno de los principales jefes militares de Juárez, el también indígena oaxaqueño Porfirio Díaz, se convertiría en dictador por más de 30 años, hasta el estallido de la Revolución Mexicana en 1910. En su gobierno, Díaz y el grupo intelectual 
extranjero que le asesoraba, llamado "científicos", impulsaron una política de modernización, basada en el apoyo a las haciendas, lo que favorecía la clase aristócrata nacional y extranjera, pero no a las clases bajas, entre ellas a indígenas, quienes fueron convertidos en peones.

Asimismo, Díaz buscaba detener los brotes de inconformidad que surgían en distintos puntos del país, utilizando a los conocidos "rurales", policías que sometían las sublevaciones. "Durante el Porfiriato se usó la fuerza para contener a los indígenas que pedían la resolución de sus demandas y se le dio amplias oportunidades a la inversión extranjera, lo que permitió que existieran grandes latifundios no nacionales en todo el país" (García Romero, 2001, p. 363).

En la Colonia el indio fue considerado tan vasallo de la Corona como los españoles, pero en realidad quedó sometido a un régimen de tutela y a una persistente represión y despojo. Sin embargo, el liberalismo mexicano destruyó más comunidades en un siglo de las que la Colonia destruyó a lo largo de 300 años. La paradoja entre la igualdad jurídica formal y la desigualdad social real ayudó al encumbramiento de un nuevo hacendado y latifundista liberal quien llegó a su plenitud durante el régimen de Porfirio Díaz. (Montemayor, 2001, p. 23)
El nacionalismo mexicano, como sus semejantes hispanoamericanos, antecedió al europeo y se manifestó con rasgos originales. El nacionalismo tuvo sustento en el patriotismo criollo, un sentimiento colectivo que en el siglo XVIII había logrado crear identidades sociales que se reconocían por el orgullo de haber nacido en una patria colmada de riqueza natural y bendecida por la aparición milagrosa de la madre de Dios, la Virgen de Guadalupe, según los dogmas católicos.

Durante la Guerra de Independencia (1810-1821), el patriotismo criollo se convirtió en discurso nacionalista. Es decir, el nacionalismo mexicano fue alimentado por la convicción de que la población y el territorio patrio no podían florecer mientras persistiera el lazo que ataba al país con un poder extranjero.

La invasión norteamericana de 1847 y la francesa de 1864-1867 convirtieron ese nacionalismo incipiente en un discurso antiimperialista y anticolonial. La humillante derrota que propinaron las tropas estadounidenses sobre las fuerzas nacionales, seguida por la pérdida de más de la mitad del territorio, trajo consigo dos consecuencias: Primera, un hondo sentimiento de culpa que obligó a emprender una revisión del concepto de nación y de las debilidades del Estado. Segunda, un cambio sustancial en la manera de pensar y hacer la política.

El liberalismo doctrinario que caracterizó a la primera mitad del siglo fue remplazado, de 
1897 en adelante, por un liberalismo pragmático, por una práctica política fundada en su capacidad para transformar la realidad. Una de las expresiones más claras de esa nueva política fue la creación de los símbolos y ritos que en adelante representaron a la nación.

En lugar de confiar la transformación del país a las constituciones, los gobiernos de Juárez, Lerdo de Tejada y Díaz, en la segunda mitad del siglo XIX, hicieron de las instituciones del Estado los instrumentos del cambio que deseaban implantar en la sociedad. Otro difusor del nacionalismo fue la que podría denominarse la "historia oficial'.

El libro de historia integró la memoria desmembrada del país en un relato coherente, que comenzaba en el lejano tiempo prehispánico y concluía en el 'próspero presente porfirista. Es decir, se dotó de unidad a tres pasados hasta entonces irreconciliables: la época prehispánica, el pasado colonial y la era republicana. (Labastida, 2001, p.397)

El mensaje uniformador que difundía el relato histórico se extendió a otras áreas de la cultura, como la literatura o la pintura. $\mathrm{Al}$ fundirse estas diversas corrientes con el proyecto político de crear el Estado nacional apareció lo que Benedict Anderson ha llamado una 'comunidad política imaginada'. Imaginada, porque los distintos miembros de ella ni se conocían ni tuvieron contacto nunca y, pese a ello, en sus mentes se instaló la idea de que pertenecían a una entidad denominada nación mexicana. Comunidad política, en fin, porque se concebía en el marco de un territorio limitado por fronteras con otras naciones y se consideraba un estado autónomo y soberano. Es decir, el nacionalismo que predicó el Estado uniformó las creencias colectivas.

La faz oscura del nacionalismo apareció en diferentes países, cuando asumió la forma de una relación nacional que situó a la nación abstracta por encima de la política y de los grupos humanos que la integraban. En todos los casos en que el nacionalismo adoptó la forma de culto político, sus mitos adquirieron el carácter de fundamentos inmutables de la nación y asumió los rasgos de una ideología intolerante, firme en rechazar cualquier concepción que tuviera otras tradiciones. El paso de los sentimientos patrióticos de finales de siglo a una ideología nacionalista manipulada por la clase dirigente hizo de ese nacionalismo una ideología oficial opuesta a cualquier otra concepción de la nación. El nacionalismo, lógicamente, recrudeció su rechazo a los grupos étnicos que sustentaban sus propias ideas de identidad. El nacionalismo porfiriano se volvió intolerante. 
La violencia contra las tradiciones comunitarias provocó un resurgimiento general de las reivindicaciones indígenas en las distintas regiones del territorio nacional que, en las lenguas más diversas, demandaban la devolución de sus tierras, respeto a sus derechos ancestrales, castigo a los crímenes de los grupos ladinos, reconocimiento de las identidades indígenas y comunitarias, protección legal para sus pueblos y lenguas, justicia, entre otras demandas. Por primera vez se escucharon sus voces.

El continuo asedio a las tierras y los derechos campesinos convirtió el problema indígena en un problema nacional. El ataque conjunto del Estado y los grupos ladinos unificó a los aislados pueblos indígenas, por ejemplo, los grupos asentados en el área maya se confederaron, formaron ejércitos numerosos y defendieron sus tierras.

Los reclamos de justicia agraria, tierra y libertad, o respeto a los derechos de los pueblos se convirtieron en lemas políticos. Por ello, a finales del siglo XIX el ataque contra las comunidades indígenas fue general, ya que una de las invenciones mejor logradas de la ideología que construyó el Porfiriato fue la definición del mestizo como síntesis de lo mexicano. ${ }^{6}$

Para finales de la primera década del siglo XX, un grupo intelectual, encabezado por Francisco I. Madero, dis-

6 CNI. http://www.laneta.apc.org/cni/mh.htm. Agosto 2007. putaría la Presidencia de la República. Después de las elecciones fraudulentas de las que fue objeto, es hecho prisionero y, en el exilio, finalmente convoca a la sublevación a través del Plan de San Luis. Porfirio Díaz es derrotado.

Sin embargo, una vez que Madero había llegado al poder, ignora al sector campesino que le apoyó. Ante ello, el Ejército Libertador del Sur (ELS), encabezado por el líder indígena campesino Emiliano Zapata, proclama su Plan de Ayala en 1911 y retoma los principios del Plan de San Luis, agregando el lema magonista de "Tierra y Libertad, la tierra es de quien la trabaja" y reafirmando las principales demandas de los pueblos indígenas y campesinos de México: la restitución de las tierras comunales.

Cuando Madero es asesinado en el episodio conocido como la "Decena Trágica", usurpa el poder el militar Victoriano Huerta, apoyado por el gobierno norteamericano, convierte en uno de sus principales enemigos a Zapata y su ejército de indígenas campesinos. Sin embargo, al norte del país surge con fuerza la resistencia en contra del usurpador, y se crea el Ejército Constitucionalista encabezado por Venustiano Carranza, exgobernador de Coahuila y hacendado en la época de Porfirio Díaz.

Entre los cuerpos del Ejército Constitucionalista destacan el Ejército del Noroeste, encabezado por Álvaro Obregón y en la región del Golfo, Pa- 
blo González, pero principalmente la llamada "División del Norte" comandada por el líder revolucionario Francisco Villa, que nunca fue reconocida como un verdadero ejército, aunque fuera más poderoso que los anteriores, debido principalmente a estar compuesta y dirigida por campesinos que antagonizaron con $\mathrm{Ca}$ rranza y Obregón.

A la caída del usurpador Victoriano Huerta, Carranza se proclama primer jefe de la Revolución y asume la Presidencia. Los ejércitos de Zapata y Villa no están de acuerdo y convocan a la Convención de Aguascalientes. Carranza pierde y se va a Veracruz, recién desocupada por el ejército invasor de Estados Unidos. Zapatistas y villistas toman la Ciudad de México $y$ encargan el gobierno al presidente surgido de la Convención, Eulalio Gutiérrez, quien huiría a integrarse a las fuerzas carrancistas.

La fuerza indígena y campesina de la Revolución Mexicana fue vencida por su propia incapacidad de formular un programa sólido para consolidar el poder real de la República. La Revolución Mexicana significó para los grupos indígenas la posibilidad de ser parte del proyecto nacional. Representados por Emiliano Zapata, el proyecto parecía tener la posibilidad de ser alternativo.

La defensa de los pueblos, su orientación agraria, su no renuncia a las formas reales de vida forjadas a través de los siglos, le otorgan al movimiento zapatista un lugar especial, diferente dentro de las corrientes que conformaron la Revolución.

No obstante, la Revolución Mexicana no significó un cambio de rumbo en lo que atañe a la población indígena, el proyecto planteaba reivindicaciones condicionadas a través de las cuales los beneficios que se otorgaban fueron al mismo tiempo los instrumentos de integración, esto es para su desindianización. (Bonfil Batalla, 2006, p.105)

A nivel nacional, además de las rebeliones por la lucha del poder entre los generales revolucionarios, se desarrolló la Guerra de los Cristeros, la cual fue derrotada en sus aspiraciones de restituir a la Iglesia los poderes que había perdido con Juárez. La rebelión de los Cristeros y el movimiento zapatista chiapaneco son consideradas las dos grandes rebeliones en contra del poder institucional posrevolucionario.

Con el presidente Lázaro Cárdenas se hizo reversible la creación de los ejidos, se protegieron las propiedades comunales y se introdujo la educación bilingüe, aunque sus sucesores no continuaron con esta política. Ante la postergación de soluciones para los pueblos indígenas, el gobierno de Miguel Alemán crea en 1948 el Instituto Nacional Indigenista (INI), 
cuyo primer centro coordinador se establecería en Chiapas, como una forma de atender y canalizar las demandas indígenas. En pleno auge de la etapa modernizadora de los gobiernos del PRI, en las décadas de 1950 y 1960 surgieron movimientos sociales, algunos con base indígena y campesina, como lo fueron el movimiento jaramillista, heredero de la lucha de Zapata en el Estado de Morelos. Su máximo dirigente, Rubén Jaramillo, fue asesinado.

Ya en la década de 1970, después de las represiones gubernamentales del 2 de octubre de 1968 y del 10 de junio de 1971, encabezadas por el entonces presidente Díaz Ordaz y luego por el siguiente presidente Luis Echeverría Álvarez, respectivamente, surge una nueva etapa en la guerra de guerrillas, que tendría uno de sus focos principales en la Sierra de Guerrero y las figuras de los maestros rurales Genaro Vázquez y Lucio Cabañas, quienes comandaban guerrillas campesinas extremadamente politizadas en la lucha de clases y la revolución social, quienes finalmente son derrotados y asesinados.

En 1974 se realiza en Chiapas el Congreso Nacional Indígena (CNI), que reunió a representantes de todos los pueblos indígenas de la entidad y del país. En él se bosquejaron lo que serían las principales directrices para resolver algunos de los principales problemas indígenas, pero poco pudo desarrollarse. ${ }^{7}$ Díaz Ordaz recortó notablemente el presupuesto destinado a la política indigenista $y$, en consecuencia, al INI. Contrariamente a Díaz Ordaz, Luis Echeverría pretendió recuperar la confianza de la sociedad e imprimió un populismo, en apoyo a las instituciones gubernamentales y no gubernamentales dedicadas de alguna manera a la atención de los pueblos indígenas.

Su sucesor López Portillo, en 1977, se pronunció porque el INI respetara la organización social, valores culturales y usos de las distintas etnias del país. En 1982, con la adopción del neoliberalismo, la política social no fue la excepción en la imposición de una serie de medidas a favor del nuevo modelo económico. Debido a que la mayor parte de la población indígena se dedica al agro, a continuación, se hace mención de algunos efectos del nuevo modelo en el campo mexicano.

Según Estela Martínez:

En el campo el Estado estableció los límites a sus actividades y obligaciones, impulsando la autonomía e independencia de la gente, factores de producción, de tal modo que se crearon las condiciones de una nueva expansión comercial y productiva a partir de las acciones que los propios factores productivos realicen, en condiciones de

7 http://www.laneta.apc.org/cni/mh.htm. Agosto 2007. 
mayor competitividad, experiencia de inversión, desarrollo técnico y aprovechamiento de las ventajas comparativas que las nuevas condiciones requieren. (Martínez Estela y Sergio Sarmiento 1996, p.319)

Con base en esta visión, a partir del gobierno de Miguel De la Madrid se da prioridad a la agroexportación, se abrió el mercado nacional, se apoyó el capital privado y se dejó al abandono el sector social. Este abandono se manifiesta en el cambio de actitud hacia la población indígena. La actividad del INI fue decreciendo y comenzó a notarse una mayor presencia de organismos no gubernamentales dedicados a la cuestión indígena.

En materia agrícola, la modernización del aparato productivo se resume en cuatro puntos básicos:

1. La reforma institucional.

2. Cambio de fomento y estímulo a la producción.

3. Reforma de la legislación agraria.

4. Modernización de las organizaciones de productores, para que sean capaces de intervenir en el diseño y puesta en marcha de políticas y programas concretos para el agro. (Martínez Estela y Sergio Sarmiento , 1996, p. 323)
Entre las décadas de 1980 y 1990 comenzaron los preparativos a nivel nacional e internacional sobre el significado del Quinto Centenario del viaje de Colón a América. Se organizó la "Campaña Continental 500 Años de Resistencia" y el Consejo Mexicano "500 Años de Resistencia Indígena, Negra y Popular", que acercó a diversas organizaciones indígenas, campesinas, obreras, populares, sindicatos, académicas y estudiantiles entre otras, en torno al rechazo a la cultura del neoliberalismo.

En marzo de 1992 se realiza la primera gran marcha indígena que atravesó el país desde Palenque, Chiapas, hasta la Ciudad de México, con las consignas sociales de defensa de los derechos humanos, cese a la represión y respeto a las autoridades propias. Para octubre de 1992 miles de indígenas toman las principales ciudades del país, manifestándose pacíficamente exigiendo que sus demandas fueran atendidas.

En San Cristóbal de las Casas, Chiapas y en Morelia, Michoacán son derribadas las efigies de los conquistadores, mientras que en la Ciudad de México se falla en el intento de derribar la de Cristóbal Colón. La Ciudad de México es el destino de dos grandes marchas de más de diez días de duración procedentes de Guerrero y Oaxaca principalmente.

Carlos Salinas accede a atender los reclamos a través del INI y la SEDE- 
SOL. Las reuniones de seguimiento de los acuerdos fueron diluyendo hasta el hastío las demandas indígenas, que llegaron a su disolución total en marzo de 1993. Diversas organizaciones indígenas emprenden nuevamente la movilización, entre ellas el Consejo Guerrerense "500 Años de Resistencia Indígena”.

Se realizan también congresos regionales y encuentros internacionales para evaluar la situación indígena de todo el continente, entre ellos el de la Coordinadora de Naciones Indígenas del Continente (CONIC) en octubre de 1993, en Temoaya, Estado de México. ${ }^{8}$

Por ello, el conflicto que renació entre el Estado nacional y los grupos étnicos en 1994 sigue siendo un conflicto del pasado, pero sobre todo difícil de resolver en el futuro por las variantes ya mencionadas.

Por una parte, porque la revisión de la historia advierte que uno de los mayores obstáculos para comprender esos fenómenos sociales ha sido la presunción errónea de que existe una sola realidad mexicana. Contra esta concepción, el proceso histórico muestra la presencia de diversas identidades, en conflicto constante unas con otras.

Por otra parte, otro error que no permite comprender realmente las identidades colec-

8 http://www.laneta.apc.org/cni/mh.htm. Agosto 2007. tivas es la que las considera como construcciones inmutables, incluso a través del tiempo -es decir, que las comunidades indígenas del pasado son las mismas que las del presente y lo serán en el futuro-, cuando la realidad es que son maleables a las influencias del exterior. (Labastida Martín del Campo, 2001, p. 404)

Este conflicto se ha agudizado en el caso de México porque vivió la trágica experiencia colonial. En lugar de reconocer la realidad híbrida que habita en los diversos ámbitos de la sociedad desde el siglo XVI, unos sectores se empeñaron en asumirse indígenas, otros renegaron de esa herencia y se identificaron con el legado occidental, y otros más reconocieron ser mestizos, pero de una forma restringida, que no incluía la plena aceptación de los otros sectores sociales.

Es decir, a partir del inicio de la vida independiente de la nación, entre el 'indio' real y el 'indio' que destruyó la Conquista y que formaba parte del pasado glorioso de México, de la mexicanidad, no había ya relación alguna. De ahí que a juicio del sector dirigente del país el 'indio' no pudiera redimirse sino gracias al contacto con el blanco. Estas imágenes perduran hasta nuestros días.

Algo de esta visión del indígena permanecía en el comunicado oficial que el gobierno de Chiapas emitió el $1^{\circ} \mathrm{de}$ 
enero de 1994, cuando surgió el Ejercito Zapatista de Liberación Nacional (EZLN): "Diversos grupos de campesinos chiapanecos que ascienden a un total de cerca de 200 individuos, en su mayoría monolingües, han realizado actos de provocación y violencia en cuatro localidades de la entidad, que son San Cristóbal de las Casas, Ocosingo, Altamirano y Las Margaritas" (Montemayor, 2001, p. 69).

|Como si la condición indígena "monolingüe" fuera sinónimo de primitivismo y violencia; como si se olvidara que la mayor parte de la población mexicana es monolingüe, ya que solo habla español, no como los tzeltales, tzotziles o mixtecos, por ejemplo, que además de su lengua materna, hablan castellano y a menudo otra lengua de la región. El nacionalismo mestizo mal entendido, el racismo escondido y las políticas indigenistas demagógicas han destruido más comunidades indígenas de las que la Colonia destruyó en trescientos años.

Sustituir la realidad de la mayoría de la sociedad mexicana es seguir desgastando la energía y los recursos de la nación, en vez de crear las condiciones para que esa realidad se transforme a partir de su propia potencialidad, esa fuerza creadora que no ha podido explayarse en todos los ámbitos, porque la dominación colonial la ha negado y obligado a la resistencia para sobrevivir.
Esa potencialidad es la civilización del México profundo; porque precisamente con esa civilización y no contra ella es como puede construirse un proyecto real, mexicano en su totalidad, que desplace al proyecto del México imaginario injusto, impráctico e ineficaz, como los hechos han demostrado que es, para crear una sociedad verdaderamente democrática. (Bonfil Batalla, 2006, p. 12)

\section{La búsqueda de reivindicación y autonomía}

A lo largo de las últimas décadas, y particularmente desde principios de los 90, en México, originado en gran parte por el surgimiento del movimiento zapatista chiapaneco, se reaviva el término indigenismo. Como ya se ha abordado en la presente investigación, el indigenismo es la ideología para fundar la acción de mejoramiento del indígena sobre una base científica. Sostiene que el pueblo indígena tiene los mismos derechos que el resto de la población, en este caso de la República Mexicana, y que es un deber del Estado integrarlo a la nacionalidad.

Obviamente, el resurgimiento del uso del término no implica que anteriormente no se hayan dado movimientos indígenas o planeado políticas indigenistas. Incluso, puede definirse la guerra de Conquista como una po- 
lítica indigenista en tanto afectó sustancialmente a la población indígena de aquella época.

En 1957, Gonzalo Aguirre Beltrán, uno de los indigenistas de mayor influencia en América, resume el núcleo del proyecto indigenista al concebirlo como "ideología del mestizaje, método y técnica de unificación nacional" (Sotres Mutio, 2003, p. 66).

En 1970 se puede fijar el inicio de dos movimientos de contestación al indigenismo que marcaron toda la década. Por una parte, se desarrolla una corriente teórica que cuestiona, desde los centros académicos, los fundamentos mismos del movimiento. A escala latinoamericana esa posición se expresa en la Declaración de Barbados, de 1971, que defiende el derecho de los pueblos indígenas a ser protagonistas de su historia y gestores de su propio destino; asimismo hace un llamado a los gobiernos, las iglesias y los equipos científicos sociales a cumplir su misión en concordancia con ese objetivo.

Simultáneamente surge otro movimiento con objetivos similares, pero, de hecho, más importante. En todos los países con población indígena comienzan a aparecer organizaciones políticas indígenas actúan en el terreno político regional, nacional y aún internacional. Surge una nueva intelectualidad constituida por personas que recuperan su identidad india tras un largo proceso de desindianización.
Ante esta situación, los gobiernos se han visto obligados a revisar sus políticas indigenistas, e incluir en las constituciones políticas locales, derechos específicos de acuerdo con los pueblos indígenas de América (Bobbio, 1976).

Porque debe explorarse la presencia de la civilización mesoamericana en otros grupos de la sociedad que no se reconocen a sí mismos como 'indios'. Aquí se pone en evidencia la desindianización, esto es, la pérdida de la identidad colectiva original como resultado del proceso de dominio colonial. El cambio de identidad, sin embargo, no implica necesariamente la pérdida de la cultura 'india', como lo prueba la realidad de las comunidades campesinas tradicionales que se identifican como mestizas. (Bonfil Batalla, 2006, p. 98)

Son dos las demandas básicas que caracterizan el movimiento indígena en México a partir de la década de 1990: la autodeterminación -de carácter reivindicatorio- y la autonomía. La cuestión fundamental del movimiento indígena actual es el tema del reconocimiento. La demanda indígena exige, en lo fundamental, que el Estado y la sociedad reconozcan a los pueblos indígenas.

Ha cambiado la perspectiva de las demandas indígenas des- 
pués de la década de 1960. Hasta aquella época, los indígenas demandaban primordialmente recursos. La tierra era la base y centro de la demanda indígena. Conformaban movimientos agraristas, de lucha por la tierra, por un espacio donde vivir y trabajar. Es por ello que eran considerados campesinos, ya que hasta ese momento no consideraban el reconocimiento étnico como el aspecto principal.

No significa que los movimientos indígenas de la década de 1990 no demanden tierra. Pero la tierra y la defensa territorial agraria y rural no es el centro de la demanda. El centro de la demanda actual es más amplio, de carácter cultural e implica a toda la sociedad nacional. Se trata del reconocimiento de la existencia de colectivos indígenas, de pueblos indígenas en el interior de la nación. Es la demanda de una sociedad multiétnica. Por ello, las reformas constitucionales en dicho sentido son un aspecto importante de discusión. (Bengoa, 2007, p. 128.)

La identidad cultural de los pueblos indígenas actuales se está reinventando, ya que se trata de hacer frente a un discurso híbrido, como menciona Néstor García Canclini. La vida indígena actual está globalizada también $\mathrm{y}$ exige preguntas sobre identidad, porque a la vez que debe mostrar su carácter indígena como pueblo, también su especificidad como comunidad, abandonar la idealización del pasado y participar en la globalidad (Bengoa, 2007). Tales son realidades y retos de los pueblos indígenas en el presente siglo. La demanda ecológica, relacionada con la indígena, lo que podría llamarse "etnoecologismo" o "ecoetnicidad", para los pueblos indígenas ha significado, en la actualidad, un reforzamiento de su discurso y de su capacidad política para establecer alianzas (Bengoa, 2007)

Respecto a la autodeterminación, también conocida como autodecisión, se puede definir como la capacidad que poblaciones suficientemente definidas, desde el punto de vista étnico y cultura, tienen para disponer de sí mismas y el derecho que un pueblo tiene dentro de un Estado para elegir la forma de gobierno que desee.

En esta definición se pueden distinguir un aspecto de orden internacional que consiste en el derecho de un pueblo a no ser sometido a la soberanía de un determinado Estado contra su voluntad, y de separarse de un Estado al que no quiere estar sujeto-derecho de independencia política- así como un aspecto de orden interno, que consiste en el derecho de cada pueblo a escoger para sí la forma de gobierno que prefiere. (Bobbio, 1976: p. 99) 
La autodeterminación hace posible que un pueblo disuelva los lazos políticos que lo han conectado a otro, si así lo considera necesario. Es un concepto íntimamente ligado con los derechos humanos. Además es un derecho a la independencia, como en el caso de los pueblos sometidos al dominio colonial; o pueblos con una identidad nacional indiscutible, que como minoría forman parte de la población de un Estado, pero que se sientan separados de ella por la historia, la cultura, el idioma, entre otros factores.

Asimismo y en forma trascendente, este principio reconoce el derecho que tienen los pueblos a constituirse como Estados independientes. Sin embargo, en la práctica se limita sólo a la descolonización y no se identifica con el derecho de secesión. (Hernández-Vela Salgado, 1996, p. 37)

Una de las formas concretas de ejercer el derecho a la libre autodeterminación es la autonomía. Es la capacidad de decidir el destino, las cuestiones y acciones más inmediatas en las comunidades.

Autonomía, en un sentido político, es la potestad particular que dentro del Estado pueden gozar municipios, provincias, regiones $\mathrm{u}$ otras entidades de éste para regir intereses peculiares de su vida interior, mediante normas y órganos de gobierno propios.

La autonomía política se puede concebir de diversas maneras: o como la independencia total de un Estado (autonomía en sentido simple) o como la descentralización del poder político en los municipios, regiones o entidades federativas (autonomía en sentido estricto). (Sotres Mutio, 2003, p. 6)

El concepto de autonomía se encuentra relacionado con el de soberanía, pero no se confunde con él. La autonomía puede darse por grados y en diferentes niveles: en el municipio, en la región, en la entidad federativa o en el Estado. La soberanía, en cambio, es la potestad suprema dentro del Estado de decidir en última instancia todo lo que corresponde al bien público, con el monopolio de la coacción física. (Jurídicas, 1992, p. 280)

En México, la autonomía política, en sentido estricto, surge como una característica del régimen federal. El Artículo 40 de la Constitución establece: "Es voluntad del pueblo mexicano constituirse en una República representativa, democrática, federal, compuesta de estados libres y soberanos en todo lo concerniente a 
su régimen interior, pero unidos en una federación establecida según los principios de esta Ley Fundamental".

Las comunidades indígenas mexicanas han buscado su autonomía cultural, política y social, lo cual implica el reconocimiento de la autonomía de los pueblos indígenas, sin afectar la unidad nacional que la propia Carta Magna establece. Supone el derecho a ejercer formas organizativas propias y capaces de articularse eficazmente con las de otros sectores culturales y sociales, también hace referencia a la tierra y la explotación de los recursos naturales. Es decir, la demanda es de autonomía en su organización política y de gobierno.

Un buen ejemplo de análisis en torno al concepto de autonomía indígena lo da Héctor Díaz-Polanco, quien señala que el régimen de autonomía busca formas de integración social que estén basadas en la coordinación y no en la subordinación de sus colectividades parciales, los conglomerados étnicos; la máxima congruencia entre pluralidad y unidad en la integración política del Estado nacional. Díaz-Polanco menciona:

- Que la satisfacción de los intereses de las diversas colectividades integrantes, incluyendo a los pueblos indígenas, sea compatible con la de la colectividad nacional-estatal, pero

9 Constitución Política de los Estados Unidos Mexicanos. que también los principios globales que rigen la vida nacional se adecuen para dejar espacio a los derechos particulares.

- Romper la rígida composición de mayoría y minoría basada en las características étnicas, con la tendencia de la primera a identificar sus intereses con los del Estado.

- Poner en práctica una solidaridad y fraternidad nacionales que se expresen en una asimetría positiva, según la cual los más rezagados en el ejercicio de derechos y en el disfrute de bienes básicos reciban apoyos especiales.

- Que la representación democrática, en la organización política y administrativa del Estado, de los pueblos y de las regiones socioculturales del país sea a tono con la plural composición étnico-nacional de la sociedad. (Sánchez, 1999, p. 110)

Entonces, la autonomía, en el sentido propuesto por Díaz Polanco, constituye un régimen jurídico-político dentro del Estado nacional, que configura un gobierno propio, o autogobierno, para que grupos determinados, con tradición histórica común y características socioculturales propias (costumbres, creencias, lengua, territorio, entre otras) puedan desarrollar libremente sus modos de vida, ejercer los derechos que les asisten 
como colectividades étnicas y manejar ciertos asuntos por sí mismos.

La autonomía es un sistema por medio del cual los grupos socioculturales ejercen el derecho a la libre autodeterminación. Así, los pueblos pueden decidirse, entre otras, por la independencia y la formación de un Estado nacional o por formas de autonomía en el marco de un Estado nacional preexistente.

En México, como en el resto de Latinoamérica, prácticamente ninguna organización indígena pretende declarar soberanía política, crear su propio Estado nacional o pronunciarse por la independencia. Lo que desean los pueblos indígenas, como se manifiesta en los diversos documentos y pronunciamientos de las propias organizaciones indígenas, es mantener y desarrollar sus propias formas de vida sociocultural en el marco nacional, lo que supone transformaciones de las relaciones opresivas y excluyentes que aún imperan.

Es decir, el régimen de autonomía resulta de un pacto sociopolítico entre el Estado y los pueblos indígenas. La autonomía no es efecto de una decisión unilateral ni de los Estados ni de las etnias, es resultado de un compromiso, de una negociación política. Como consecuencia de tal compromiso, se establecen los marcos jurídico-políticos y las formas institucionales que habrán de garantizar el logro de los propios integrantes, ya que la autonomía regional es un sis- tema que implica cierta descentralización administrativa, pero también política del Estado.

A partir de ubicar la autonomía como una demanda étnica, existe una relación estrecha de esta misma con las formas de gobierno indígena como una práctica histórica vigente. El gobierno indígena tiene distintas modalidades y grados y, en general, opera en el ámbito que puede llamarse la costumbre indígena comunitaria; corresponde a un espacio geográfico, cuyas fronteras están dadas justamente por las formas de gobierno y no por la localidad.

La mayoría de las comunidades indígenas en México ha conservado y recreado formas de organización y un sistema de toma de decisiones colectivo que constituye un sistema político complejo, estructurado alrededor del principio de que la comunidad es una carga compartida. Este sistema ha sido conocido en la antropología mexicana como "las formas de gobierno indígena". Estas se constituyen cotidianamente en las siguientes áreas de competencia:

- Normas generales de comportamiento.

- Conservación del orden interno.

- Definición de derechos y obligaciones de los miembros.

- Reglamentación sobre el acceso y la distribución de los recursos naturales. 
- Definición y tipificación de delitos y faltas.

- Sanción a la conducta delictiva de los individuos.

- Manejo, control y solución de conflictos y disputas.

- Definición de funciones y cargos de la autoridad.

El sistema político indígena se rige por principios como el consenso, el interés común, el cumplimiento de obligaciones colectivas y el comportamiento personal en la familia y en la comunidad. A él corresponde un sistema de cargos, el cual comprende una gama de funcionarios que, sin sueldo de por medio, cumplen tareas asignadas por consenso en la asamblea respectiva.

En general, este sistema de cargos se organiza de manera rotativa, los cargos superiores otorgan prestigio $y$ las personas que llegaron a ellos es porque a lo largo de su carrera han aprendido a gobernar, han demostrado calidad moral en el desempeño de sus tareas y la vida comunitaria.

Desde la asamblea general se establecen jerarquías con responsabilidades, funciones y atribuciones claramente delimitadas. El cargo mayor corresponde al de gobernador, y de ahí se desprende una escala de grupos de trabajo y comités, además de mensajeros, ayudantes y policías comunita- rios. Cada comité o grupo de trabajo guarda a su vez un alto grado de autonomía, pero cualquier persona, incluidos el gobernador y el juez, puede ser destituida en cualquier momento si la asamblea lo determina.

Generalmente existe una tradición de que las personas mayores que han llegado a los grados más altos y han cumplido satisfactoriamente con sus tareas de gobierno, constituyen el grupo de "los pasados", los ancianos o los tatas, quienes como grupo tienen la función de un cuerpo consultivo y asesor de asuntos difíciles. Aunque en épocas recientes se observa una tendencia a la disminución del poder de los grupos de ancianos.

Si durante mucho tiempo los cargos estuvieron en asociación cívico-religio$\mathrm{sa}$, actualmente tienden a diferenciarse para permitir la tolerancia religiosa, política, social, cultural o lingüística.

Algo semejante ocurre en el derecho, en el cual predomina que las faltas administrativas y los delitos menores sean atendidos por la autoridad indígena y los delitos mayores, o los conflictos entre un indígena o un mestizo, por la autoridad judicial o municipal correspondiente.

La organización social indígena es un mecanismo de cohesión que se ha ejercido sin reconocimiento al interior de las comunidades, por lo que la articulación entre los dos sistemas, el estatal y el indígena, ha creado con- 
flictos cada vez más frecuentes que han establecido una competencia con evidente desventaja y desgaste para la autoridad indígena.

Esta desventaja se debe fundamentalmente a:

- El desconocimiento generalizado de las formas de organización indígena; el cual se relaciona con que hasta hace poco no existía un reconocimiento de la composición pluriétnica de la nación.

- La vieja actitud de querer 'civilizar' a los 'indios', alejándolos de su cultura e integrándolos a la cultura y lengua nacionales.

- La resistencia indígena, la cual ha consistido en la aceptación formal de la institucionalidad nacional, redefinida al interior de las comunidades, con apego a su historia y acervo jurídico-cultural.

- La sociedad indígena, cuya existencia se basa en los derechos colectivos que privilegian los intereses comunales sobre los individuales.

- El sistema de toma de decisiones, el cual parte del principio del consenso y de los valores compartidos, donde la asamblea general es la máxima autoridad. Lo anterior podría ser juzgado por un analista superficial como el 'voto a mano alzada, susceptible a un alto grado de manipulación, fundamentalmente por no ser secreto, $y$ fuente de presión. (Avila, 2000, p. 358)
Sin embargo, debido precisamente al consenso, las minorías y las discrepancias tienen cabida legítimamente. Es decir, es una forma distinta de ejercer la democracia. En este sentido, la redefinición de la institucionalidad ha dado lugar a que detrás de un agente municipal se esconda un juez o gobernador indígena, y en planos como el religioso se encuentren ídolos detrás de los altares. Lamentablemente, en algunos casos la organización indígena para sobrevivir ha negociado, pero también disfrazado y escondido sus espacios.

\section{Conclusiones}

Durante las últimas décadas, la demanda de autonomía se ha convertido en una bandera de lucha para los pueblos indígenas de México y América Latina, pero debido a sus distintos usos e implicaciones en las normas internacionales, genera confusión y temores separatistas en los Estados.

En la conceptualización y formulación de la autonomía se encuentran diversas ideas y propuestas, cuyos alcances van desde el ámbito regional y municipal hasta lo local. Ello complica aún más el cumplimiento de tan importante demanda, sobre todo en el ámbito nacional. La autonomía es así una demanda central del conjunto de reivindicaciones asociadas a los derechos indígenas que actualmente también se debaten en el marco internacional y al interior de numerosas naciones. Esta demanda se refiere a 
la autodeterminación de los pueblos, básicamente en el espacio geográfico propio, en su mayoría de tipo rural.

La condición pluriétnica como base del establecimiento de ámbitos de autonomía indígena se inició ya en los países de habla sajona, donde destaca el caso de Canadá en el cual los derechos territoriales también abarcan los recursos naturales. En América Latina destacan los casos de Bolivia, Venezuela, Colombia y Nicaragua en los cuales la autonomía indígena ha sido elevada a rango constitucional.

Sin embargo, parece que predomina una fuerte resistencia de los Estados nacionales para avanzar en este reconocimiento, provocando que el movimiento indígena latinoamericano se haya orientado a la conquista de la autodeterminación debido a múltiples factores entre los cuales se destacan:

- Un proceso de globalización que ha ido acabando con lo que se llamo 'las regiones de refugio'.

- Los cambios han sido producto del surgimiento, también mundial, de los movimientos impulsados por las propias comunidades indígenas.

- La existencia vigente desde la óptica indígena de usos, costumbres y sistemas políticos propios, generalmente llamados 'formas de gobierno indígena'.
- Las 'regiones de refugio' eran zonas inaccesibles o poco comunicadas a las que habían sido empujadas y relegadas las comunidades indígenas, donde tenían una existencia casi autárquica. Actualmente, estas regiones se muestran como áreas con gran cantidad de recursos naturales, forestales y minerales. Por ello se ha acelerado su trasformación bajo la lógica del mercado y de los megaproyectos orientados a la construcción y el desarrollo de presas, así obras de infraestructura diversa, además del turismo. (Avila, 2000, p. 360)

Lo cierto es que la identidad étnica es una cuestión decisiva para entender la cultura del Estado-nación. En México, desde el período posterior a la Independencia y hasta la mitad de la década de 1970, la política oficial del Estado consistió en asimilar a los pueblos indígenas a la cultura mestiza, como ya se señaló. Pero, a partir de la segunda parte de la década de 1970, sobre todo posterior a la realización del Congreso Indígena de Pátzcuaro, Michoacán de 1975, y debido fundamentalmente a la creciente organización política de los pueblos indígenas, el Estado mexicano abandonó oficialmente su política de asimilación al tomar la iniciativa de organizar a los pueblos indígenas en asociaciones étnicas separadas. Además:

El levantamiento indígena en Chiapas, el $1^{\circ}$ de enero de 1994, fue el clavo que cerró el ataúd 
de las políticas de asimilación del Estado. De manera clara $y$ en repetidas ocasiones, el EZLN y el movimiento indígena nacional señalan que los indígenas son excluidos de la nación, por lo que demandan ser tratados como ciudadanos mexicanos con todos sus derechos, sin por ello renunciar a su identidad indígena, que se da de facto, por ejemplo en la Ley de Usos y Costumbres de Oaxaca, y que no ha desaparecido desde la Conquista, a pesar de la oposición del Estado Mexicano que basa su política étnica en el mestizaje biológico y cultural que ya se ha expuesto". (Hernández, 2002, p.230).

Es decir, en la actualidad, la lucha del EZLN y el movimiento indígena nacional han propuesto un proyecto nacional alternativo, cuyo centro consiste en la movilización de las bases. En este proyecto, la incorporación a la nación no proviene "desde arriba", sino "desde abajo", desde el pueblo, ya que se puede ser mexicano o mexicana al mismo tiempo que pertenecer a otras comunidades a nivel local o regional.

Por supuesto, el otro de los puntos cruciales en el movimiento indígena nacional ha sido la insistencia en que el Estado reconozca los derechos colectivos de los pueblos indígenas, ya que, según el Estado, ataca directamente las bases mismas de la ciudadanía y nacionalismo mexicanos, basados en los derechos individuales.

\section{Referencias}

Avila, A. (2000). Autonomía y formas de gobierno indígena. En el Estado del desarrollo económico y social de los pueblos indígenas de México 1996-1997. México: INI.

Bengoa, J. (2007). La emergencia indígena en América Latina. Chile: Siglo XXI.

Biblio Juridicas Unam. (s. f.). Obtenido de biblio.juridicas.unam. mx: http://biblio.juridicas.unam. $\mathrm{mx} / \mathrm{libros} / 2 / 512 / 4 . \mathrm{pdf}$

Bobbio, N. y. (1976). Diccionario de política. México: Siglo XXI.

Bonfil, G. (2006). México profundo. Una civilización negada. México: De bolsillo.

CDI. http://www.cdi.gob.mx/index. php?id_seccion $=90$. Diversidad etnolingüística. Julio 2007.

CDI. http://www.cdi.gob.mx/index. php?id_seccion=399. Indicadores socioeconómicos. Agosto 2007.

Congreso Nacional Indígena. (CNI). http://www.laneta.apc.org/ cni/mh-mni.htm\#02. El movimiento indígena nacional. Agosto 2007.

CNI. http://www.laneta.apc.org/cni/ mh-mni.htm\#02. Agosto 2007.

CDI. http://es.wikipedia.org/wiki/Indigenismo. Agosto 2007.

CNI. http://www.laneta.apc.org/cni/ mh-mni.htm\#02. Agosto 2007. 
CDI. http://es.wikipedia.org/wiki/Indigenismo. Agosto 2007.

CNI. http://www.laneta.apc.org/cni/ mh-mni.htm\#02. Agosto 2007.

CDI http://www.laneta.apc.org/cni/ mh.htm. Agosto 2007.

CDI. http://www.laneta.apc.org/cni/ mh.htm. Agosto 2007.

García, J. (2001). El fracaso del neoliberalismo en materia de política social en América Latina en la década de los noventas: El caso de resurgimiento de los movimientos indígenas. México: Facultad de Estudios Superiores Aragón.

Hernández, R. A. (2002). Tierra, libertad y autonomía: Impactos regionales del zapatismo en Chiapas. México: Centro de Investigaciones y Estudios sobre Antologia Social e Internacional Work Group for Indigenous Affairs.

Hernández-Vela Salgado, E. (1996). Diccionario de política internacional. México: Porrúa.

Jurídicas, P. e. (1992). Diccionario jurídico mexicano. México: Porrúa e Instituto de Investigaciones Jurídicas.

Labastida Martín del Campo, J. y. (2001). Globalización, iden- tidad y democracia. México y América Latian. México: Siglo XXI y UNAM.

León, M. (2002). Visión de los vencidos. Relaciones indígenas de la Conquista. México: UNAM.

Martínez Estela y Sergio Sarmiento (1996). Campesinos e indígenas ante los cambios de la política social, En Las políticas sociales de México en los años noventa. México: Plaza y Valdés.

Montemayor, C. (2001). Los pueblos indios de México hoy. México: Planeta.

Pozas, R. e. (1998). Los indios en las clases sociales de México. México: Editorial México.

Rosas, B. F. (7 de 1995). México índigena: Un perfil estadístico. En Educación 2001 (p. 32).

Sánchez, C. (1999). Los pueblos indígenas: Del indigenismo a la autonomía. México : Siglo XXI.

Sotres , L. y. (2003). Glosario de términos del conflicto chiapaneco. Coordinación para el diálogo y la negociación en Chiapas. México: $\mathrm{CDNCH}$.

Recibido: 11/3/2016 • Aceptado: 15/9/2016 